\title{
Enucleation of a Giant Prostatic Hyperplasia in Ghana: A Case Report and Mini Literature Review
}

\author{
Alexander K. Egote ${ }^{1}$, Paul Poku Sampene Ossei², John Taylor ${ }^{2}$, Theophilus Bortier1 \\ ${ }^{1}$ Department of Surgery, Urology Unit, Brong Ahafo Regional Hospital, Sunyani, Ghana \\ ${ }^{2}$ Department of Pathology, School of Medical Sciences, Kwame Nkrumah University of Science and \\ Technology, Komfo Anokye Teaching Hospital, Kumasi, Ghana \\ Email: *alexanderegote@yahoo.com
}

How to cite this paper: Egote, A.K., Ossei, P.P.S., Taylor, J. and Bortier, T. (2018) Enucleation of a Giant Prostatic Hyperplasia in Ghana: A Case Report and Mini Literature Review. Case Reports in Clinical Medicine, 7, 583-593.

https://doi.org/10.4236/crcm.2018.712053

Received: October 11, 2018

Accepted: November 27, 2018

Published: November 30, 2018

Copyright $\odot 2018$ by authors and Scientific Research Publishing Inc. This work is licensed under the Creative Commons Attribution International License (CC BY 4.0).

http://creativecommons.org/licenses/by/4.0/

\begin{abstract}
Herein we report a patient with a prostatic hyperplasia weighing exactly $700 \mathrm{~g}$ which was successfully removed at the Brong Ahafo Regional Hospital theatre in Ghana by Pfannesteil Transvesical Simple Prostatectomy. A prostatic hyperplasia of enormous size is very uncommon and to the best of our knowledge, only ten of such cases have been previously reported. The case report presented here constitutes the eleventh heaviest prostate reported in medical literature and also forms the first case report of giant prostatic hyperplasia from Ghana.
\end{abstract}

\section{Keywords}

Benign Prostatic Hyperplasia, Prostatectomy, Transvesical, Case Report

\section{Introduction}

Benign prostatic hyperplasia (BPH) in males has been shown to be commonly associated with the ageing process [1] [2]. As a man ages, the enlarged prostate usually produces obstructive and irritative lower urinary tract symptoms. The size of the prostate is independent of symptoms [3] and smaller size may produce symptoms whereas bigger size may not. In some people, the prostate enlarges massively (weighing more than $500 \mathrm{~g}$ ) consequently developing into a giant prostatic hyperplasia (GPH) [4] [5]. Despite its undesirable effects, researchers have not identified any specific cause for this massive enlargement of the prostate. The case under discussion is a patient who was in his usual state of health till about 2 weeks prior to presentation when he complained of difficulty 
in passing urine and stools. He experienced symptoms of straining on micturition, weak stream, intermittency and incomplete emptying of the bladder. $\mathrm{He}$ also complained of frequency and nocturia.

He suffered an episode of acute retention of urine about a week prior to presentation and was rushed to a peripheral health facility and consequently to our facility for further management. Examination of the patient revealed a massive prostate enlargement weighing exactly $700 \mathrm{~g}$. The prostate's large size and the relative lack of symptoms prior to patient presentation further explained the fact that symptoms do not necessarily correlate with the size of the prostate. To the best of our knowledge, this is the eleventh largest benign prostatic hyperplasia presented in medical literature. Though our patient could not survive in this case, we provide recommendations and suggestions to advance surgical treatment.

\section{Case Report}

This is an 88-year-old male retired civil servant with no history of alcohol or tobacco use and no known history of any chronic condition. He was in his usual state of health till about 2 weeks prior to presentation when he complained of difficulty in passing urine and stools. He experienced symptoms of straining on micturition, weak stream, intermittency and incomplete emptying of the bladder. He also complained of frequency and nocturia. He suffered an episode of acute retention of urine about a week prior to presentation and was rushed to a peripheral health facility. A suprapubic catheter was passed to relieve the obstruction after a failed urethral catheterization, but he was subsequently noticed to have experienced an episode of heamaturia and was referred to our facility (Brong Ahafo Regional Hospital in Sunyani, Ghana) for expert urological care on $1^{\text {st }}$ March 2018.

Examination revealed an elderly male, conscious, alert but confused. He was not pale, not febrile and had no bipedal edema. He had no prior history of any chronic condition, and this was the first episode of acute retention of urine. He also had no known family history of BPH or prostate cancer. Pupils were about $2 \mathrm{~mm}$ in size and reacted directly and consensual to light. Tone and reflexes in both upper and lower limbs were normal but power in the lower limbs could not be objectively assessed. The abdomen was soft, full, non-tender with a huge suprapubic mass. His blood pressure was 130/70 $\mathrm{mmHg}$, pulse was 96 beats-per-minute and jugular veinous pressure was not raised. The first and second heart sounds were present and normal with apex beat in the Left $6^{\text {th }}$ intercostal space, anterior axillary line. Respiratory rate was 22 cycles/minute, air entry was adequate bilaterally and breath sound was vesicular with no added sounds. Digital rectal examination revealed good anal hygiene and normal sphincter tone. The prostate was enlarged (about $12 \mathrm{~cm} \times 15 \mathrm{~cm}$ ) with a smooth surface, well defined edges, firm consistency, non-tender, non-obliterated median sulcus and a mobile rectal mucosa over the surface of the prostate. An initial impression of Urine retention 
due to lower urinary tract obstruction and bleeding BPH was made with a differential diagnosis of prostate cancer. Patient was admitted to the ward for the following work-up and treatment:

1) Blood investigations; full blood count, renal function test, PSA, liver function test, fasting lipid profile;

2) Radiological Investigations; urological ultrasound scan;

3) Parasitology; Urine R/E and Urine $\mathrm{C} / \mathrm{S}$.

After laboratory investigation (Table 1) and examinations, a diagnosis of lower urinary tract obstruction (LUTO) due to bleeding benign prostatic hyperplasia (BPH) complicated by urinary tract infection (UTI) was confirmed. Patient was started on: Tab. Ciprofloxacillin $500 \mathrm{mg} 12$ hourly, Tab. Metronidazole $400 \mathrm{mg} 8$ hourly, Tab. Tranexamic Acid 500 mg 8 hourly and haemotransfusion of 2 units of packed cells. Also, 3 units of packed cells were grouped and saved for theatre and patient was subsequently prepared for an open simple Transvesical Prostatectomy.

\section{Surgery}

Patient was operated upon $7^{\text {th }}$ March 2018. Under sterile condition and spinal anaesthesia, patient was well draped, pfannesteil incision was made through the fascia (Figure $1 \&$ Figure 2). Rectus muscles retracted longitudinally through it fibres, bladder opened in transverse to expose huge adenomatosed prostate occupying the whole bladder wall (Figure 3). Enucleation with the right index finger with support of the left index finger in the rectum was made. Findings were giant lobed prostate tissue (Figure 4). A 3 Way $22 \mathrm{~F}$ silicon catheter was placed at the fossa of the enucleated prostate and its balloon inflated with $40 \mathrm{ml}$ distilled water to achieve haemostasis. It served the purpose of continuous bladder drainage. Massively distended bladder was closed in 2 layers with vicryl 2 (Figure 5). Drainage tube was placed in the pelvis. Rectus muscle apposed with vicryl 0 and fascia with nylon 2, subcutaneous layer with vicryl 2/0 and skin with nylon $2 / 0$.

Table 1. Laboratory investigation report of patient.

\begin{tabular}{|c|c|}
\hline Test & Result \\
\hline Full Blood Count & $\begin{array}{l}\text { WBC }-12.14 \times 10^{9} / \mathrm{L} \text { (High)with elevated Neutrophils (83.15\%), } \mathrm{Hb}-14.6 \mathrm{~g} / \mathrm{dL} \text { (Normal), Platelets }-296 \times 10^{9} / \mathrm{L} \\
\text { (Normal) }\end{array}$ \\
\hline Liver Function Test & Globulin-1.9 g/dL (Low), Indirect bilirubin-1.2 mg/dL (High), Albumin/Globulin-2.6 (High) \\
\hline BUN, Cr & BUN-62 (High), Cr-2.0 (High) \\
\hline Lipid Profile & Normal \\
\hline Urological Ultrasound & $\begin{array}{l}\text { Prostate gland was grossly enlarged with heterogeneous echogenicity and ill-defined margins protruding } \\
\text { through the base of the urinary bladder. It measures } 12.5 \times 10.44 \times 8.48 \mathrm{~cm} \text { and a volume of } 573 \mathrm{~cm}^{3} \text {. Urinary } \\
\text { bladder appeared displaced but of normal shape and wall thickness. }\end{array}$ \\
\hline Urine $\mathrm{RE}+\mathrm{CS}$ & $\begin{array}{l}\text { Leukocytes-+, Protein-+, Blood-+++, Glucose-Trace, Puss cells }-10 \text { hpf, Red Blood Cells }->30 \text { hpf, } \\
\text { Epithelial Cells }-2 \text { hpf }\end{array}$ \\
\hline Culture & Citrobacter species were isolated. Viable count $-<10^{2} \mathrm{CFU} / \mathrm{mL}$, Gram Stain - Gram negative rods seen \\
\hline Sensitivity & Microbes were resistant to all antibiotics tested for \\
\hline
\end{tabular}




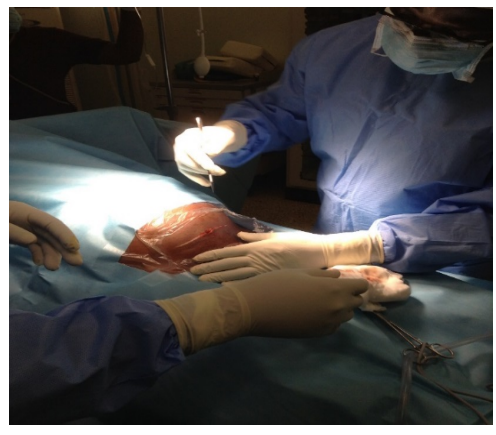

Figure 1. Grossly distended lower abdomen above the umbilicus due huge adenomatosed prostate.

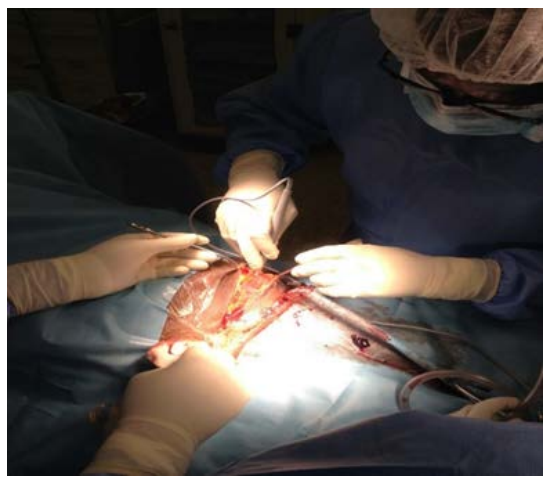

Figure 2. Surgery in Progress.

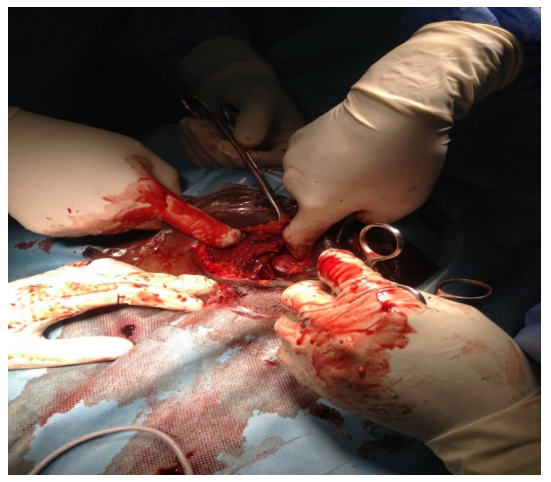

Figure 3. Grossly distended bladder wall totally filled with huge prostate tissue (about $1.5 \mathrm{~L}$ of blood clots).

Post operation condition was satisfactory. Patient was haemotransfused 2 paint of packed cells after operation. The enucleated prostate weighed exactly $700 \mathrm{~g}$ (Figure 6) and sample specimen was sent for histopathology examination at the pathology department, Komfo Anokye Teaching Hospital, Kumasi, Ghana.

Histopathology report: Sections showed prostate with proliferation of stroma and glands. The glands gave a cystic dilation with bland epithelium and intact basal cells. There were numerous corpora amylocae. These features were in 


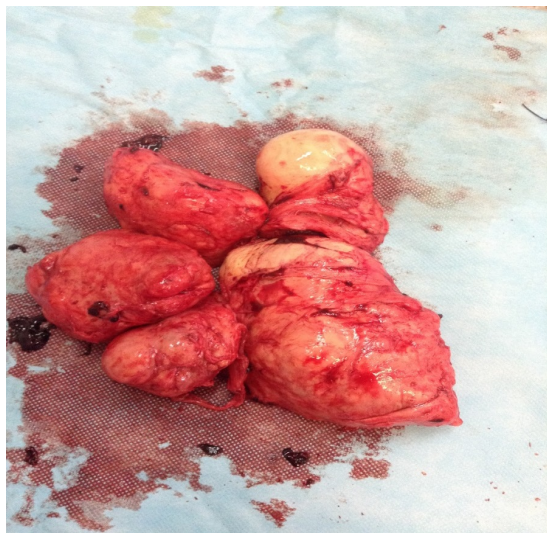

Figure 4. Giant prostate specimen.

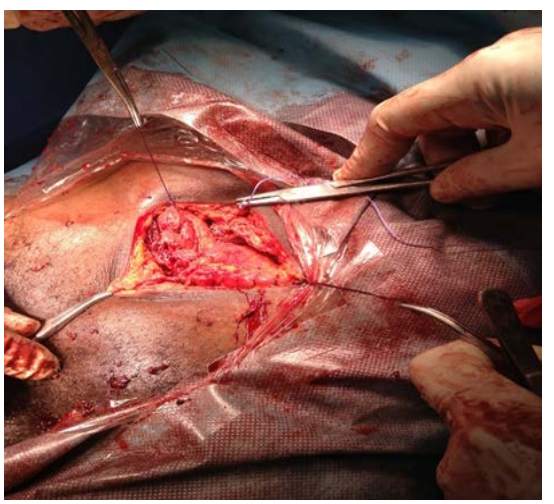

Figure 5. Double layer closure of bladder with vicryl 2.

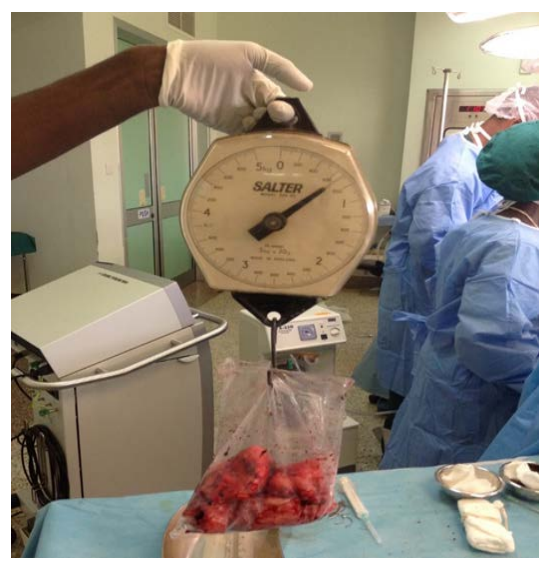

Figure 6. Enucleated prostate specimen weighed $700 \mathrm{~g}$.

keeping with benign hyperplasia. A diagnosis of benign nodular hyperplasia was made (Figure 7).

Immediate post op. condition was satisfactory and the post op. plan included;

1) Monitoring of vital signs half hourly until the patient recovered fully from anaesthesia, and then 4 hourly subsequently. 


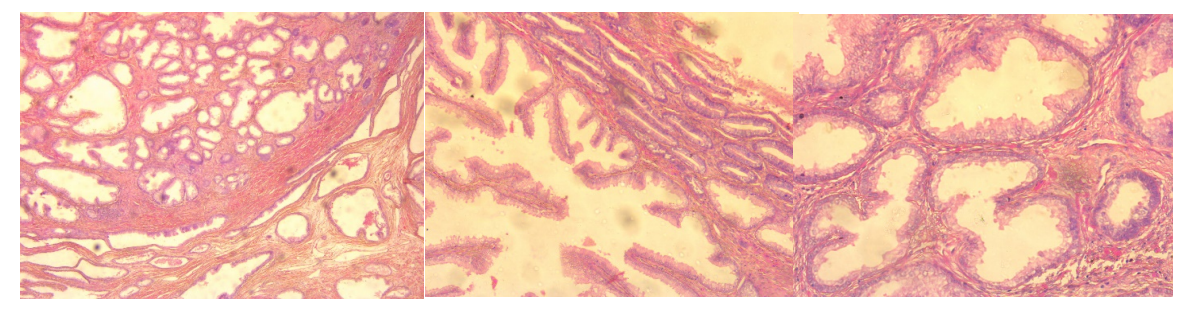

Figure 7. Sections of prostate showing benign nodular hyperplasia.

2) Continuous irrigation for 24 hours.

3) IV Ceftriaxone 2 g 12 hourly for 24 hours.

4) IV Metronidazole $500 \mathrm{mg} 8$ hourly for 24 hours.

5) IM Pethidine $100 \mathrm{mg} 12$ hourly for 24 hours.

6) IV Paracetamol 1 g 8 hourly for 3 days.

\subsection{Post 0p Day 1}

Patient had no complaints. Both suprapubic and urethral catheter was draining blood stained fluid from continuous irrigation. Wound dressing was soaked, temperature was $37.6^{\circ} \mathrm{C}$, pulse was 87 beats/min (Regular and of good volume) and $\mathrm{BP}$ and RBS measured 110/50 $\mathrm{mmHg}$ and $12.1 \mathrm{mmol} / \mathrm{L}$ respectively.

Plan was to; Continue treatment. Change wound dressing, continue bladder irrigation for another 24 hours and check post op FBC.

\subsection{Post 0p Day 2}

Patient complained of persistent hiccups. Suprapubic and urethral catheters were draining much clearer urine. Wound dressing was soaked, temperature was $35.4^{\circ} \mathrm{C}$, pulse was 80 beats $/ \mathrm{min}$ and $\mathrm{BP}$ also measured 130/60 $\mathrm{mmHg}$. Chest was clinically clear and respiration rate and, RBS measured $20 \mathrm{cycles} / \mathrm{min}$ and $8.4 \mathrm{mmol} / \mathrm{L}$ respectively.

Plan was to; Continue treatment, stop continuous irrigation, change wound dressing, encourage patient to mobilize, administer IV Chlorpromazine $50 \mathrm{mg}$ stat, then $25 \mathrm{mg} 8$ hourly for 72 hours.

\subsection{Post 0p Day 3}

Patient was drowsy after the administration of stat dose of IV Chlorpromazine. Both urethral and suprapubic catheters were draining slightly blood-stained urine. Body temperature was $37.5^{\circ} \mathrm{C}$, Pulse measured 92 beats/min, BP measured $130 / 70 \mathrm{mmHg}$ and respiration rate was 22 cycles/min but chest was clinically clear. GCS and RBS also measured 13/15 and $11.3 \mathrm{mmol} / \mathrm{L}$ respectively.

Plan was to; Stop IV Chlorpromazine, continue other medications, change wound dressing, hydration with IV fluids; IV Normal Saline-1.0 L, IV Ringers Lactate $-1.0 \mathrm{~L}$ and IV Dextrose Saline-1.0 L

\subsection{Post 0p Day 4}

Patient had regained full consciousness and had no complaints, dressing was 
soaked, catheters were draining clear urine, temperature remained unchanged $\left(37.5^{\circ} \mathrm{C}\right)$, pulse was 94 beats/min, $\mathrm{BP}$ was $170 / 60 \mathrm{mmHg}$ and respiration rate was 20 cycles/min. Chest was clinically clear and RBS also measured $8.6 \mathrm{mmol} / \mathrm{L}$.

Plan was to; continue treatment, change wound dressing, encourage ambulation, encourage adequate oral feeding and liberal fluid intake.

\subsection{Post Op Day 5}

Patient was feeding poorly and had difficult mobilization, dressing was soaked, temperature measured $38.0^{\circ} \mathrm{C}$, Pulse was 116 beats/minute, BP measured $180 / 60 \mathrm{mmHg}$ and respiration rate was $26 \mathrm{cycles} / \mathrm{min}$. There was bronchial breath sounds on the right upper and middle zones of the lungs with an FBS of $10.4 \mathrm{mmol} / \mathrm{L}$. An impression of a hypostatic pneumonia was made.

Plan was to; Do a full blood count and check for malaria parasites, add tab Azithromycin $500 \mathrm{mg}$ daily for 7 days, Zincovit 1 tab daily for 14 days, continue other medications, start physiotherapy and change wound dressing. Encourage adequate feeding and liberal oral fluids intake.

\subsection{Post Op Day 6}

Patient was still feeding poorly with $\mathrm{FBC}$ results of WBC-19.65 with neutrophilia, $\mathrm{HB}-7.1 \mathrm{~g} / \mathrm{dL}$ with normal $\mathrm{MCV}$ and $\mathrm{MCH}$, Platelets $-244 \times 10^{9} / \mathrm{L}$ and MPs-no malaria parasites seen. Catheter was draining bloody urine and dressing was soaked. Temperature measured $37.6 .0^{\circ} \mathrm{C}$, pulse measured 90 beats $/ \mathrm{min}$ and BP also measured 140/60 mmHg. Respiration rate was $23 \mathrm{cycles} / \mathrm{min}$ with bronchial breath sounds on the right upper and middle zones of the lungs. FBS measured $11.3 \mathrm{mmol} / \mathrm{L}$.

Plan was to; Continue treatment, haemotransfuse a unit of whole blood, change wound dressing, continue physiotherapy and encourage adequate feeding and liberal oral fluid intake.

\subsection{Post Op Day 7}

Patient was doing well and was feeding and taking in oral fluids satisfactorily. Mobilization was however not encouraging, dressing was soaked, temperature measured $37.6^{\circ} \mathrm{C}$, pulse was 98 beats $/ \mathrm{min}$, BP was $130 / 70 \mathrm{mmHg}$ and respiration rate also measured 23 cycles/min. Examination revealed bronchial breath sounds on the right upper and middle zones of lungs.

Plan was to; Continue treatment, change wound dressing, continue physiotherapy, encourage adequate feeding and liberal oral fluid intake.

\subsection{Post Op Day 8}

Patient was doing well and was feeding and taking in oral fluids satisfactorily. Mobilization was still not encouraging. Dressing was soaked, Catheters were still draining bloody urine, Temperature $-36.6^{\circ} \mathrm{C}$, Pulse -84 beats $/ \mathrm{min}, \mathrm{BP}-130 / 60$ $\mathrm{mmHg}$, Respiration Rate-23 cycles/min with Bronchial breath sounds on the 
right upper and middle zones of the lungs. FBS levels measured $8.3 \mathrm{mmol} / \mathrm{L}$.

Plan was to; Continue treatment, change wound dressing, continue physiotherapy, encourage adequate feeding and liberal oral fluid intake.

\subsection{Post Op Day 9}

Patient had suddenly tipped into a state of unconsciousness with a GCS of 6/15. He had labored breathing, urine was still blood stained, temperature- $37.6^{\circ} \mathrm{C}$, pulse -118 beats/minute, $\mathrm{BP}-130 / 80 \mathrm{mmHg}$ and respiration rate measured 28 cycles/min with bronchial breath sounds on the right upper and middle zones. Tone and reflexes were decreased and power in all limbs could not be objectively assessed. RBS also measured $12.5 \mathrm{mmol} / \mathrm{L}$. An impression of a thromboembolic phenomenon was made with differentials of pulmonary embolism and cerebrovascular accident.

Plan was to; Pass a feeding tube, give intranasal oxygen at a flow rate of $4 \mathrm{~L} / \mathrm{hr}$, Start IV Fragmin 5000 IU daily for 72 hours, urgent CT scan of chest and brain, stop Tab tranexamic acid and continue other medications. About 2 hours after initiation of treatment, patient went into cardiac arrest. Cardiopulmonary resuscitation was started and after 6 cycles, there was still no cardiopulmonary activity. Patient was therefore declared biologically dead. An informed consent was obtained from the patient's family to report the case.

\section{Discussion}

$\mathrm{BPH}$ is a common disorder of the prostate affecting most males above the age of 40 years [2]. Prostatic hyperplasia is considered to be due to the proliferation of epithelial and stromal cells, impairment of programmed cell death (apoptosis) or both and is endocrine controlled [6]. Autopsy data (2010-2017) from our facility (Brong Ahafo Regional Hospital) indicate that over 90\% of men older than 80 years have histological evidence of BPH. According to Maliakal et al., 2014, prostates weighing more than $100 \mathrm{~g}$ has been recorded in only $4 \%$ of men above the age of 70 years [7] and only 10 cases of BPH where the prostate weighed more than $700 \mathrm{~g}$ has been reported in medical literature to date [6]-[15] with the highest recorded by Medina-Peres et al., in 1997 [6]. In all of these cases only six (6) patients could recover from the enucleation. Massive hematuria due to $\mathrm{BPH}$, although uncommon is often associated with haemodynamic instability that require urgent resuscitative measures, including volume replacement, control of bleeding and subsequently definite treatment of the enlarged prostate. In the experience of the Brong Ahafo Regional Hospital in Sunyani, Ghana open prostatectomy is the mainstay of treatment because of limited resources and the fact that most patients present late and with complications of BPH. It is known that elderly patients with co-morbid medical conditions such as diabetes and hypertensive heart disease presenting with $\mathrm{BPH}$ complicated by bleeding are best treated by open prostatectomy after initial resuscitation. In the case of our patient, he did not have any prior history of co-morbid conditions but showed ep- 
isodes of high BP and RBS whilst on admission. His age and estimated size of the prostate together with the complication of bleeding made an open prostatectomy the best operative choice. Initial resuscitation measures were taken and the surgery was done only after he was clinically stable.

Surgery was successful without any complication, and immediate post op condition was satisfactory. The challenge with his management was however during the post operation period. Most post operation patients are encouraged to ambulate after surgery, a situation we found challenging during his post op management. Lack of ambulation puts post op patients at risk of thromboembolic phenomena, hypostatic pneumonia and the development of pressure sores [16]. In our case, patient developed hypostatic pneumonia and pressure sores during the post op period due to a lack of proper ambulation. An attempt at physiotherapy was initiated which proved futile. The use of antifibrinolytic agents and vitamin $\mathrm{K}$ injection to control the persistent bleeding during the post op period further put him at risk of a thromboembolic phenomenon. Use of anticoagulants such as fragmin also put our patient at risk of increased bleeding. In such a treatment dilemma, the best choice would have been to control bleeding with close monitoring. Perhaps monitoring the patient's International Normalized Ratio would have given an indication of a risk of thromboembolic event. It was therefore not surprising, the sudden tipping into a state of coma after post op day 9 which could likely be as a result of a thromboembolic phenomenon. It is also important to identify co-morbid conditions in elderly patients presenting with complications of $\mathrm{BPH}$. In the case of our patient, although he had no prior history of co-morbid conditions, fluctuations in BP and moderately high RBS could have been an indication of an underlying hypertension or diabetes. Perhaps an ECG, chest X-Ray or an FBS with glycated hemoglobin estimation could have identified co-morbid conditions which could have been co-managed with physicians to ensure a more successful outcome. Identification and management of co-morbid conditions could have probably ensured early ambulation after surgery to avert the usual complications associated with lack of post op ambulation. Despite the general attribution of prostate diseases to old age, it is also known that age has no influence on the pathophysiology of prostate disease but instead provide the timeframe needed for factors such as lifestyle and genetic influence to have impact on the prostate. Considering the fact that prostate cancer progresses slowly and the symptoms (often not suggestive of prostate cancer) manifest late in life, most men are often unaware they have the disease. Periodic checkups and immediately opting for treatment helps in the early management and treatment of the disorder.

\section{Conclusion and Recommendation}

In certain cases, surgical treatment of prostate hyperplasia has ended fatally due to the after effects of haemorrhage. In order to tackle the risk of haemorrhage effectively, we recommend the technique of inflation of catheter balloon at the 
base of enucleated prostate with 6-hour traction and continuous bladder irrigation to stop bleeding in large and vascular prostates. This technique was applied effectively in our case and yielded an excellent outcome. It is also interesting to note that ultrasound scan report estimated prostate volume of $573 \mathrm{~cm}^{3}$ which did not correlate to surgical volume of $700 \mathrm{~cm}^{3}$.

\section{Ethical Approval}

Ethical clearance was sought form the Research Ethics Committee of the Brong Ahafo Regional Hospital.

\section{Conflicts of Interest}

The authors declare no conflicts of interest regarding the publication of this paper.

\section{References}

[1] Berry, S.J., Coffey, D.S., Walsh, P.C. and Ewing, L.L. (1984) The Development of Human Benign Prostatic Hyperplasia with Age. The Journal of Urology, 132, 474-479. https://doi.org/10.1016/S0022-5347(17)49698-4

[2] Egote, A.K., Ossei, P.P.S., Agyemang-Duah, E., Quarshie, E. and Taylor, J. (2018) Age as a Risk Factor for Prostate Diseases: A 6-Year Selective Prospective Study among Males in the Brong Ahafo Region of Ghana. JMR, 4, 154-157.

[3] McVary, K.T., Roehrborn, C.G., Avins, A.L., Barry, M.J., Bruskewitz, R.C., Donnell, RF., et al. (2011) Update on AUA Guideline on the Management of Benign Prostatic Hyperplasia. The Journal of Urology, 185, 1793-1803. https://doi.org/10.1016/j.juro.2011.01.074

[4] Soichiro, O., Masahiko, M., Michihiro, Y., Yoshinobu, K., Masaaki, Y., Yuichi, S., et al. (2012) A Giant Prostatic Hyperplasia Treated by Open Surgery. International Journal of General Medicine, 5, 1009-1012.

[5] Joseph, C.P. (2000) Neoplasms of the Prostate Gland. In: Tanagho, E.A. and McAninch, J.W., Eds., Smith's General Urology, 15th Edition, Lange Medical Books/McGraw-Hill, New York, 399.

[6] Medina, P.M., Valero, P.J. and Valpuesta, F.I. (1997) Giant Hypertrophy of the Prostate: 2,410 Grams of Weight and $24 \mathrm{~cm}$ in Diameter. Archivos españoles de urología, 50, 795-797.

[7] Maliakal, J., Mousa, E.E. and Menon, V. (2014) Giant Prostatic Hyperplasia: Fourth Largest Prostate Reported in Medical Literature. Sultan Qaboos University Medical Journal, 14, e253-e256.

[8] Ockerblad, N.F. (1946) Giant Prostate: The Largest Recorded. The Journal of Urology, 56, 81-82. https://doi.org/10.1016/S0022-5347(17)69778-7

[9] Luke, W., Davis, P. and McMillana, K. (2016) A Case of Giant Prostatic Hyperplasia. Asian Journal of Urology, 3, 53-55. https://doi.org/10.1016/j.ajur.2015.10.004

[10] Tolley, D.A., English, P.J. and Grigor, K.M. (1987) Massive Benign Prostatic Hyperplasia. Journal of the Royal Society of Medicine, 80, 777-778. https://doi.org/10.1177/014107688708001218

[11] Üçer, O., Başer, O. and Gümüş, B. (2011) Giant Prostatic Hyperplasia: Case Report and Literature Review. Dicle Medical Journal, 38, 489-491. 
https://doi.org/10.5798/diclemedj.0921.2011.04.0072

[12] Nelson, O.A. (1940) Largest Recorded Prostate. The Urologic and Cutaneous Review, 44, 454-455.

[13] Gilbert, J.B. (1939) One-Stage Suprapubic Prostatectomy for a Gland Weighing 713 Grams (One and One-Half Pounds). The Urologic and Cutaneous Review, 43, 309-310.

[14] Wadstein, T. (1938) The Largest Surgically Removed Hypertrophied Prostate. $J A M A, 110,509$. https://doi.org/10.1001/jama.1938.62790070004008b

[15] Lantzius-Beninga, F. (1966) Prostate of World Record Size. Journal of Urology \& Nephrology, 59, 77-79.

[16] Azhar, R.A., Bochner, B., Catto, J., Goh, A.C., Kelly, J., Patel, H.D., Pruthi, R.S., Thalmann, G.N. and Desai, M. (2016) Enhanced Recovery after Urological Surgery: A Contemporary Systematic Review of Outcomes, Key Elements, and Research Needs. European Urology, 70, 176-187. https://doi.org/10.1016/j.eururo.2016.02.051 